\title{
Risk Analysis and Stability Assessment on the Suspended River of the Lower Reaches of the Yellow River
}

\author{
Changli Liu, Xiuyan Wang, Miying Yin, Hongbing Hou, and Hua Dong
}

\begin{abstract}
Thanks to the increasingly-improved flood-control engineering projects in the lower reaches of the Yellow River safety has been maintained over the past 50 years. Nonetheless, the rising trend of the riverway bed of the lower reaches has not been reversed. This has been a potential hazard to the local people. Using various investigation methods we basically ascertain the geological environment of the lower reaches including active faults, crust uplift, ground subsidence, seismic activities, engineering conditions of dike foundation, hydraulic conditions and fluvial geomorphology, etc. Based on the comprehensive analysis of the instability modes and corresponding influencing factors we choose fuzzy comprehensive assessing method to assess the ground stability, dike-foundation stability and riverway stability and general stability of the suspended river. The results show that the stability of the suspended river of the Yellow River could be classified into four grades, i.e. "basically stable, unstable, very unstable and extremely unstable" and 11 segments. Taking into account future tectonic faults, earthquake, difference between riverway and ground outside riverway, riverway shapes, historical breaches, ground fluidization and seepage deformation, etc., we further find out 17 the most unstable sites, among of which 7 are the most possible breaching sites, i.e. Wuzhi, Zhongmou, Kaifeng, Fengqiu, Dongming, Changyuan and Dong'e. Calculations of the possible inundation scope and area, number of affected people, economic losses and environment damage etc. Any of them, if breached, could bring about disaster results in the lower reaches of the Yellow River.
\end{abstract}

Index Terms-Lower reaches of the Yellow River, geo-environmental characteristics, suspended river, stability assessment, risk analysis

\section{INTRODUCTION}

The Yellow River is the second largest riverway in China. It originates from Bayankala Mountains and runs through Qinghai, Ningxia, Shanxi, Henan and other provinces and finally enters into the Bohai Sea in Shandong province with a length of $5464 \mathrm{~km}$ [1]. It is the 'mother River' of Chinese nations that nurtures thousands million of local people. Nonetheless, the periodic inundation, breaches and riverway diversions in the lower reaches (within Henan province and Shandong province) have brought about disasters to the local people. The huge amounts of sediments eroded from the upper reaches have been silted within the lower reaches. This has raised the riverway bed year after year and formed the 'suspended river' that is much higher than the off-bank ground surface. The hanging degree is generally $3-5 \mathrm{~m}$, the highest is $10 \mathrm{~m}$ [1], [2]. Such a hanging-riverway situation

Manuscript received April 14, 2013; revised July 10, 2013.

Changli Liu is with Institute of Hydrogeology and Environmental Geology, Chinese Academy of Geological Sciences, Shijiazhuang, 050061, China (e-mail: urgeology@163.com). might cause serious flood disaster due to dike breach that leads to riverway diversion. Historical records show that up to 1500 breaches have occurred in the lower reaches, so had 26 riverway diversions, among of which, five diversions were the most significant. Over the past 50 years Chinese government has invested considerably to build flood-control engineering system that has prevented riverway diversion. But the suspended river has been still a potential danger to the local people.

The stability of the suspended river could be defined as its capacity to safely transport sediment and water. When such a capacity loses, the suspended river loses its stability and experiences dike damage or overflows, which leads to flood inundation and huge losses of people's life and properties. Therefore, it is important to assess the stability of the present suspended river and analyze its risk in order to harness and develop the Yellow River.

\section{THE GEOLOGIC ENVIRONMENT OF THE LOWER REACHES OF THE YELLOW RIVER}

Through systematic and comprehensive study of available data in combination of regional geology, neo-tectonic movement, fluvial geomorphology and other factors, and using remote sensing technique, field geo-environmental survey together with geophysical, geological drilling and laboratory tests etc. we did 1:50,000 and 1:100,000 image interpretation and 1:50,000 geo-environmental map-filling, and ascertained the geo-environmental characteristics of the riverway zones of the lower reaches of the Yellow River and factors affecting the stability of the suspended river. The results are shown on the geo-environmental map of the riverway zones of the lower reaches of the Yellow River (Fig. 1).

\section{ANALYSIS OF THE FACTORS AFFECTING THE StABILITY OF THE SUSPENDED RIVER}

It is found that the stability of the suspended river of the lower reaches of the Yellow Riverway is determined by crust stability, dike foundation stability and riverway bed stability. Factors affecting these three stabilities are right those affecting the stability of the suspended river [3]-[5].

\section{A. Factors Affecting the Ground Stability in the Lower Reaches of the Yellow River}

\section{1) Active faults}

Active faults have been Controlling mechanism of active fault over the riverway stability, Fig. 2 is the map showing the geological tectonism and distribution of active faults in the lower reaches of the Yellow River [2], [3]. There are 
many active faults crossing the Yellow River,

Hidden active faults(Fig. 1-B) controlling the running course of the suspended river,Previous studies [2], [3], [5] show that hidden active faults could control the running course of the Yellow River (Fig. 1-B) and sedimentation boundary, especially, riverway-crossing faults or fault-merging sites have controlled historical breach sites.
Damage to the foundation of dike engineering by riverway-crossing active faults. The six riverway-crossing deep, big faults, i.e. the F1, F2, F3, F4, F5, F6 in Fig. 2 have been all active since the Cenozoic Era [2]. They could trigger strong earthquakes that lead to ground fissure and subsidence, water \& sand eruption and thus the damage to the dike engineering.

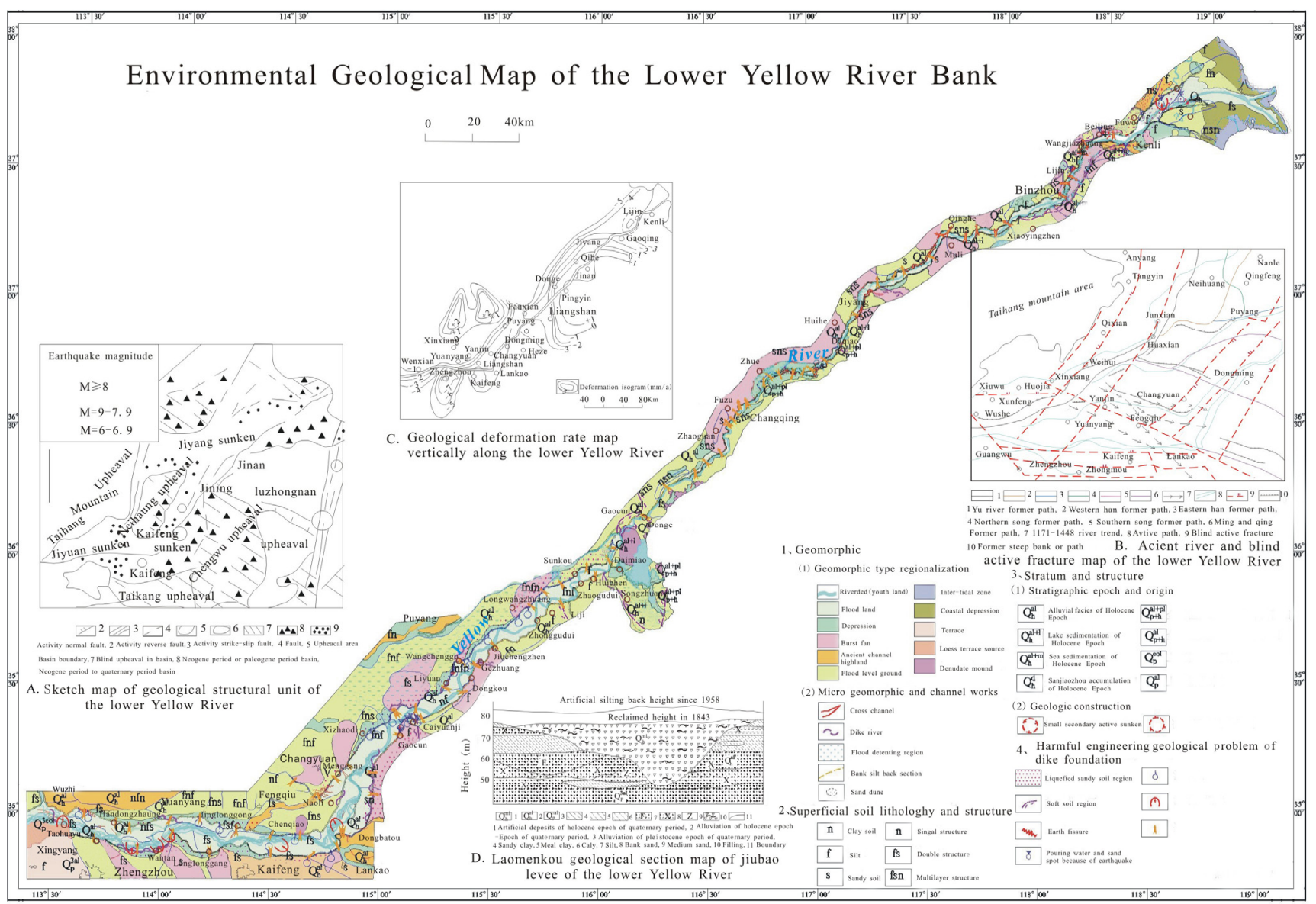

Fig. 1. Environmental geological of the lower yellow river bank

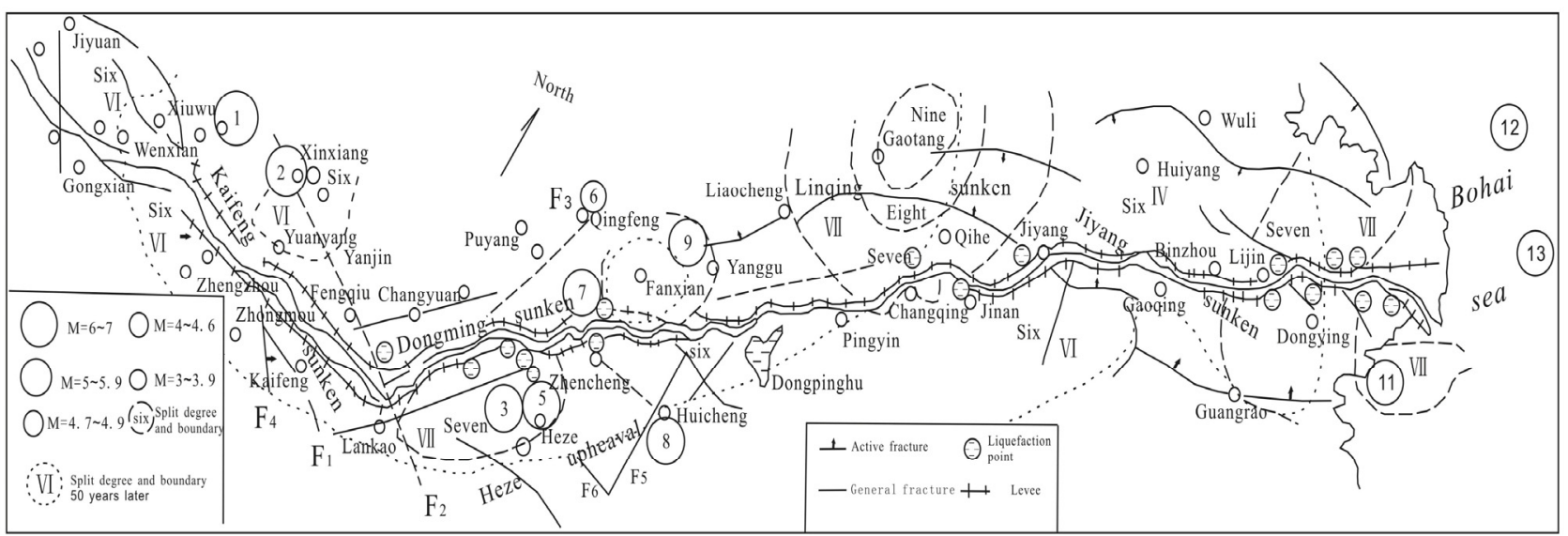

Fig. 2. Map showing the tectonic faults in the lower reaches of the Yellow River

1) The Yellow River runs through the Luzhongnan Uplift after leaving the Liangshan, the Luzhongnan uplifting's influence on the riverway stability(Fig. 1-A). Recently, modern subsidence centers have determined the scope of running course. The Yellow River mostly runs along the subsidence centers in geological time and historical time. Depression is much larger than that of its southern part (Fig. 1-C).
2) A number of intensity six or above earthquake occurred in the lower reaches of the Yellow River, most of them are related to the previously mentioned active faults. Epicenters all lie in the merging site of faults or fault belts. Earthquakes could cause big damage to the riverways of the lower reaches of the Yellow River (Fig. 1-A). 


\section{B. Factors Affecting the Stability of Dike Foundation of} the Suspended River in the Lower Reaches.

The factors include fluvial geomorphology, fluvial hydrodynamics, low quality soil of the dike foundation, historical distribution of the brust sites, soil structure inside the riverway, etc.

\section{ASSESSMENT On THE Stability OF THE SUSPENDED RIVER OF THE LOWER REACHES OF THE YELLOW RIVER}

\section{A. Assessment Method}

Fuzzy mathematic comprehensive method [5]-[7] could take into account the different level of factors affecting the stability of the suspended river with higher accuracy. Specifically speaking, we firstly choose assessment factors and determine the assessment standard for each single index, and then weigh each single index, finally use fuzzy matrix compound computation method to obtain a comprehensive result.

\section{B. Assessment Results of the Stability of the Suspended River}

According to the above-introduced assessment method, the chosen sites are assessed one by one and the results are reported on Table I and Fig. 3.

1) Results of crust stability, dike-foundation stability and riverway stability are shown in Fig. 3.

2) Results of general stability of the suspended river is shown in Fig. 3. Fig. 3 indicates that a total of 17 unstable segments could be classified in the whole lower reaches of the Yellow River, including basically stable segment, unstable segment, very unstable segment and extremely unstable segment. The location and major geo-environmental characteristics of each segment are reported on Table I.

TABLE I: COMPREHENSIVE ASSESSMENT ON THE STABILITY OF THE SUSPENDED RIVER IN THE LOWER REACHES OF THE YELLOW RIVER

\begin{tabular}{|c|l|l||}
\hline \hline Stability grade & \multicolumn{1}{|c|}{ Segment location } & Major geo-environmental characteristics \\
\hline Basically stable & $\begin{array}{l}\text { Mainly distributed in } \\
\text { Pingyinciancheng-Qihezhaoguanzhen, } \\
\text { Qihefuzudian-Jinanhuashanzhen }\end{array}$ & $\begin{array}{l}\text { Crust is stable, fault structure is less developed, ground deformation is minor, no } \\
\text { larger-than-5-intensity earthquake occurred, stable meandering riverway }\end{array}$ \\
\hline unstable & $\begin{array}{l}\text { Distributed in } \\
\text { Qihezhaoguanzhen-fuzudian, } \\
\text { Jinanhuashanzhen-Jiyang and } \\
\text { Jiyangwangjiaquan }\end{array}$ & $\begin{array}{l}\text { Less-developed fault structure, only Qiguang fault crosses the Yellow Riverway in } \\
\text { Jiyang but the ground deformation is minor, 5-6 intensity earthquake infrequently } \\
\text { occurs, stable riverway evolution, soils under the dike foundation are silty soil, silty } \\
\text { clayer soil and partially soft soil with a more-than-five-meter buried depth. Many } \\
\text { potential danger sites within the dike body. }\end{array}$ \\
\hline Very unstable & $\begin{array}{l}\text { Zhengzhouhuanghedaqiao-Dongbatou,D } \\
\text { ongpinghu-Pingyin,Jiyang-Houwangjiaq } \\
\text { uanandLijinnansong-Huanghehekou }\end{array}$ & $\begin{array}{l}\text { Crust is very unstable, faults are developed, earthquake and ground deformation are } \\
\text { intensive, dike foundation is unstable, liquefied sandy soil and clayey soil, riverway is } \\
\text { wide, shallow and disordered with string ditches etc., soils below the dike foundation } \\
\text { are laminated silty soil and sandy soil. Second flood land is developed in Dongbatou } \\
\text { and riverway shape changes frequently. }\end{array}$ \\
\hline Extremely unstable & $\begin{array}{l}\text { Zhengzhouhuanghedaqiao and } \\
\text { Dongbatou-Dongpinghu. }\end{array}$ & $\begin{array}{l}\text { Fault structures are widely developed, strong intensity 7-8 earthquakes with strong } \\
\text { ground deformation, intensively fluidized sandy soil and clayey soil below the dike } \\
\text { foundation, loose soil structure, many potential danger sites, big ratio of transverse } \\
\text { gradient to longitudinal gradient, riverway is wide and curved and sways a lot, } \\
\text { transverse and oblique streams easily occur, water likely erodes the dike directly and } \\
\text { causes the dike collapse. }\end{array}$ \\
\hline
\end{tabular}

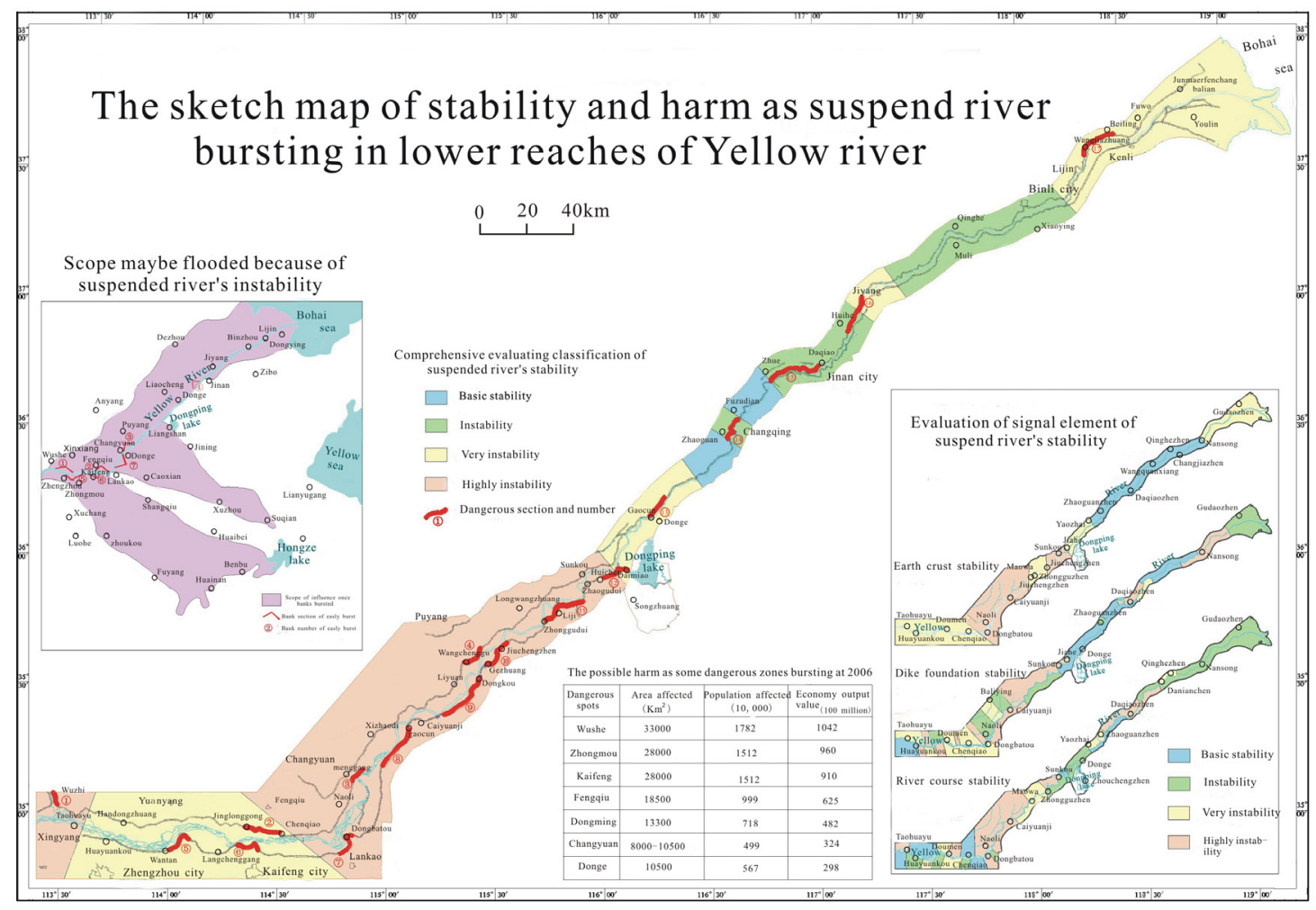

Fig. 3. The sketch map of stability and harm as suspended river bursting in lower reches of Yellow River 


\section{Risk ANALYSIS OF STABILITY-LOOSING OF THE SUSPENDED RIVER}

The comprehensive assessment shows that the stability of the suspended river is classified into four grades, i.e. extremely unstable, very unstable, unstable and basically stable and eleven segments. Except for the basically stable segmentsof Pingyincinchang-Xihezhaoguanxhen and Qihefuzudian-Jinanhuashanzhen, other segments are extremely unstable, very unstable or unstable, having the potentiality of loosing stability by breaching. So, where the breach site will be in the next 50 years and how big the riskis?

\section{A. Predicting the Breach Sites}

Considering the future earthquake, the hanging degree, riverway shape, historical breaches, soil fluidization and seepage deformation etc. as well as the situation that no measure is taken to harness the suspended river there are possibly 17 most unstable sites, i.e. Wuzhi, Fengqiu, Changyuan, Wangchenggu, Zhongmou, Kaifeng, Dongbatou, Dongming, Licunzhen-Dongkou in the 11 segments. The locations and controlling factors are shown on Fig. 3.

\section{B. Disaster Analysis of Typical Danger Sites}

1) Danger to the society and economy in the lower reaches

On the basis of the present investigation data and Ye's work [2], [8], [9] we calculated the possible inundation areas of Wuzhi, Zhongmou, Kaifeng, Dongming, Changyuan, Dong'e seven danger sites. They are $33000 \mathrm{Km}^{2}$, $28000 \mathrm{Km}^{2}, \quad 28000 \mathrm{Km}^{2}, \quad 18500 \mathrm{Km}^{2}, \quad 13300 \mathrm{Km}^{2}$, $8000-10500 \mathrm{Km}^{2}, 10500 \mathrm{Km}^{2}$, respectively. According to the relevant data of 2003 Chinese City Yearbook [10] we estimated the population density, economic development level of these regions and then calculated the losses of people, land and economy in Wuzhi, Zhongmou, Kaifeng, Dongming, Changyuan, Dong'e (Fig. 3C).

\section{2) Damage to transport, communication and important engineering projects}

The breach of the lower reaches of the Yellow River could affect major railway lines such as Jingguang line, Jinpu line, Longhai line and Xinhe line as well as road network. It could also affect the Yinhuangjiqing, Jijing, Jijin and other hydraulic engineering projects and irrigation system, Zhongyuan oil field and Shengli oil field and communication facilities. Flood will cause different level of damage to these infrastructure facilities.

\section{3) Influence on embankment and nearby ecological environment}

Flood water from breach site could exert huge influence on the environment at both sides of the riverway: a) flood invades other streams and disturbs the water system and destroys docks \& riverway-harnessing engineering. Flood could also invade lakes and reduce their storage capacities. b) flood could cause the change of riverway and lake biology species \& diversity, reduce environmental capacity of water body and worsen water pollution. c) flood could transport and diffuse rubbish, industrial waste, municipal sewage, and cause environmental pollution and disease spreading.

\section{Suggestion on Maintaining the Stability of the Suspended River}

Once the suspended river losses its stability very serious social, economic and ecological problems might arise. In addition to regulating water $\&$ sediment and strengthening soil conservation in the middle and upper reaches of the Yellow River more investment should be put to carry out geo-environmental investigation and monitoring of the lower reaches to ascertain the regional active faults, engineering geological conditions of dike foundation and various hidden dangers. This could provide detailed, reliable scientific bases for the harnessing and developing of the Yellow River.

\section{REFERENCES}

[1] Q. W. Chen, M. Q. Xu, and C. J. Yao, Harnessment of the Yellow River and utilization of water resources, Huanghe Hydraulics Press, pp. 467-471, 1988

[2] Q. C. Ye, L. Y. You, and J. X. Xu, Developing trend and environmental effects of the suspended river of the Yellow River, Huanghe Hydraulics Press, pp. 156-160, 1997.

[3] Institute of Hydrogeology and Environmental Geology, "Investigation and assessment of major geo-environmental problems of the lower reaches of the Yellow River," research report, pp. 205-218, 2003

[4] X. F. Huanpu, L. H. Tian, X. H. Liu, "Analysis of the riverway stability factors of the lower reaches of the Yellow River," World Geology, vol. 22, pp. 64-68. 2003

[5] H. J. Zimmermann, Fuzzy Set, Theory and its Applications, 3rd Edition, Kluwer Academic Publishers, Boston, 1996.

[6] C. Carlsson and R. FullEer, Fuzzy reasoning in decision making and optimization, Physica-Verlag, Heidelberg, 2002.

[7] D. Y. Feng and S. B. Lou, Fuzzy mathematics and its application, Earthquake Press, 1985.

[8] Z. C. Lu, Y. F. Jia, and Y. Z. Cao, "Possible breach sites and their inundation areas," Geography Research, vol. 6, pp. 452-458, 1987

[9] J. S. Liu, "Role of big riverways in land development and improvement," Renmin Huanghe, vol. 6, pp. 331-336. 1985

[10] Compiling committee of the society of Chinese urban development, Chinese City Yearbook, pp. 611-678, 2003

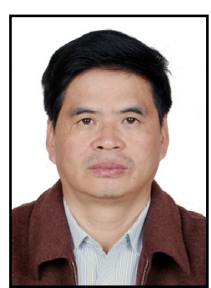

Liu Changli was born on December 24, 1963, China He graduated from Chinese Academy of Geological Sciences and received Doctor of Engineering, 1997. He was major in study includes groundwater pollution control and groundwater ecology, hydrogeochemistry and human existing environment, urban geology and suitability assessment of urbanized geological environment and geological disposal of solid wastes. 